\title{
A Comparative Study of Intravenous Clonidine and Dexmedetomidine on Characteristics of Bupivacaine Spinal Anesthesia
}

\author{
Shailender Bamel', Nandita Kad ${ }^{1}$, Vinit ${ }^{1}$, Shilpa Popli ${ }^{1}$, Devender Chahal ${ }^{1}$ \\ ${ }^{1}$ Department of Anaesthesiology, PGIMS Rohtak, Haryana, India.
}

\section{Abstract}

Background: Spinal anesthesia with bupivacaine is administered routinely for lower abdominal and lower limb surgeries. The ensuing nerve block is sufficient to ensure patient's well being, while motor block facilitates the surgeon's work. In patients receiving spinal anaesthesia, with local anesthetic agents like bupivacaine, the addition of another drug as adjuvant prolongs the analgesia. The present study is designed to study the effect of dexmedetomidine (D) and Clonidine (C) on the duration of motor and sensory block as well as postoperative analgesia by intrathecal bupivacaine in patients undergoing lower limb orthopedic surgery. Subjects and Methods: This study was carried out on 90 patients in the age group of 18 to 50 years, belonging to the American Society of Anesthesiologists(ASA) physical status I and II presenting for lower limb orthopedic surgery were included in the study. Patients were divided randomly into 3 groups. Group D received $1 \mu \mathrm{g} \mathrm{kg}^{-1}$ of dexmedetomidine, group $\mathrm{C}$ received $2 \mu \mathrm{g} \mathrm{kg}-1$ of clonidine and group NS Control group received an equivalent amount of normal saline. Results: From the current study we observed that single dose of $1 \mu \mathrm{g} \mathrm{kg-1}$ dexmedetomidine over 20 minutes started 20 minutes after spinal block and a single dose of $2 \mu \mathrm{g}$ kg-1 Clonidine resulted in a significant prolongation of time to two-segment regression, postoperative analgesia, sensory block and motor block with the maintenance of hemodynamic parameters. Intravenous dexmedetomidine was more effective than Clonidine at the prolongation of time to two-segment regression, postoperative analgesia, sensory block and motor block of spinal anesthesia with $0.5 \%$ hyperbaric bupivacaine. Conclusion: Dexmedetomidine ( $1 \mu \mathrm{g} \mathrm{kg}-1)$ in comparison to Clonidine $(2 \mu \mathrm{kg}-1)$ and placebo is far more effective in the motor blockade, sensory blockade and duration of postoperative analgesia.

Keywords: Dexmedetomidine, Clonidine, sensory block, motor block, analgesia, spinal anaesthesia.

Corresponding Author: Dr. Shailender Bamel, PG IIIrd year, Department of Anaesthesiology, PGIMS Rohtak, Haryana, India. Email: Shailender.bamel@gmail.com

Received: May 2020

Accepted: May 2020

\section{Introduction}

Spinal anesthesia is a form of neuraxial regional anesthesia involving the injection of a local anesthetic or opioid into the subarachnoid space. The degree of neuronal blockade depends on the amount and concentration of local anesthetic used and the properties of the axon. To enhance the properties of spinal anesthesia, various drugs have been tried and tested. Dexmedetomidine and Clonidine are two such drugs we are using in present study. Clonidine is a partially selective agonist for $\alpha-2$ adrenoreceptors. It is known to increase both sensory and motor block of local anesthetics. It also causes a reduction in the amount or the concentration of local anesthetic required to produce postoperative analgesia. ${ }^{[1]}$ Dexmedetomidine is a member of the alpha-2 agonist that has been reported to have cardiovascular stabilizing, analgesic, sedative, sympatholytic, opioidsparing effects and shorten the onset of both sensory and motor block while prolonging the effect of a block. ${ }^{[2]}$

In this study we evaluated and compared the effects of single-dose intravenous dexmedetomidine and Clonidine on the duration of motor and sensory block as well as postoperative analgesia in patients undergoing lower limb orthopedic surgery under the subarachnoid block with bupivacaine.

\section{Subjects and Methods}

The present study was conducted in the Department of Anaesthesiology and Critical Care, Pt. B.D. Sharma PGIMS, Rohtak in a prospective placebo-controlled and double-blind, randomized manner. Ninety patients in the age group of 18 to 50 years, belonging to the American Society of Anesthesiologists (ASA) physical status I and II presenting for lower limb orthopedic surgery were included in the study. All patients received $2.5 \mathrm{ml}$ of $0.5 \%$ hyperbaric bupivacaine intrathecally. Patients were randomly allocated on the basis of a chit system into three groups, with 30 patients in each group irrespective of gender. The study drug was made to 20 $\mathrm{ml}$ of final volume and was administered as an intravenous bolus 20 min after the subarachnoid block.

Group D (n-30): Patients received a single dose of $1 \mu \mathrm{g} \mathrm{kg}-1$ of dexmedetomidine intravenously.

Group C (n-30): Patients received a single dose of $2 \mu \mathrm{g} \mathrm{kg}-1$ intravenous Clonidine. 
Group NS (n-30): Control group received an equivalent amount of normal saline

Following administration of drugs time of administration of block, the highest level of sensory block in segments, time to achieve the highest level of sensory block, degree of a motor block by Bromage score prior to surgery, time of the start of surgery, time to achieve 2 segment regression of sensory blockade, time of completion of surgery, time of regression of motor block Bromage score zero), time of complete regression of sensory block (S1dermatome), need of diclofenac injections post-op, a total duration of surgery, a total duration of motor block, total duration of sensory block, time to voids, any other complications (dizziness, fatigue, shivering, tremors, headache, hypertension and dose of ephedrine if required, bradycardia etc.), intraoperative sedation score and other parameters such as heart rate, respiratory rate, blood pressure, $\mathrm{SpO} 2$ etc. were recorded.

Motor block onset and regression of motor block were done according to Bromage scale. ${ }^{[3]}$

\begin{tabular}{|l|l|l|}
\hline Grade & Criteria & Degree of block \\
\hline I & Free movement of legs and feet & Nil (0\%) \\
\hline II & $\begin{array}{l}\text { Just able to flex knees with free } \\
\text { movement of feet }\end{array}$ & Partial (33\%) \\
\hline III & $\begin{array}{l}\text { Unable to flex knees, but with free } \\
\text { movement of feet }\end{array}$ & Almost complete (66\%) \\
\hline IV & Unable to move legs or feet & Complete (100\%) \\
\hline
\end{tabular}

Sedation was assessed according to the Modified Wilson Sedation Scale. ${ }^{[4]}$

\begin{tabular}{|l|l|}
\hline Score & Description \\
\hline 1 & $\begin{array}{l}\text { Oriented; eyes may be closed but can respond to "Can you tell me } \\
\text { your name?" "Can you tell me where you are right now?" }\end{array}$ \\
\hline 2 & $\begin{array}{l}\text { Drowsy; eyes may be closed, arousable only to command: } \\
\text { "(name), please open your eyes." }\end{array}$ \\
\hline 3 & Arousable to mild physical stimulation (earlobe tug) \\
\hline 4 & Unarousable to mild physical stimulation \\
\hline
\end{tabular}

Sensory block was assessed by alcohol swab (cold perception) and dermatomal levels were tested every two minutes until the highest level has stabilized for four consecutive readings. Testing was conducted every 20 minutes until the point of 2 segment regression of the block. To this point, dermatomal testing was conducted by an anesthetist blinded to the patient group. Data regarding the highest dermatomal level of sensory blockade, the time to reach this level from the time of injection, time to $\mathrm{S} 2$ sensory regression was recorded.

Statistical analysis was performed by the SPSS program for Windows, version 17.0 . Continuous variables are presented as mean $\pm \mathrm{SD}$, and categorical variables are presented as absolute numbers and percentages. Normally distributed continuous variables were compared using ANOVA. For all statistical tests, a p-value of less than 0.05 was taken to indicate a significant difference.

\section{Results \& Discussion}

In this study, the time of first request for analgesia was significantly prolonged in the dexmedetomidine group than clonidine and control groups. This could be attributed to the mechanism of action of dexmedetomidine, which differs from Clonidine in being eight to ten times more selective to $\alpha 2$-adrenoceptors, especially for $\alpha 2 \mathrm{~A}$ and $\alpha 2 \mathrm{C}$ subtype of this receptor. Similar results were found by Jetly et al, Kumar et al, and Patil et al. in their studies.2,5,6

In group NS mean time to sensory level to regress two dermatome levels was $112.60+20.86$ minutes. P-value was statistically highly significant on comparison of group D with group $\mathrm{NS}(\mathrm{p}<0.001)$ while it was significant on comparison of group D V/S group $\mathrm{C}(\mathrm{p}<0.05)$ and group $\mathrm{C}$ V/S group NS $(p<0.05)$. Similarly in a study done by Jetly et al. the time for two-segment regression was significantly longer with dexmedetomidine $(146.5 \pm 12.5 \mathrm{~min} ; \mathrm{p}<0.001)$ and Clonidine (138.9 $\pm 17.4 \mathrm{~min} ; \mathrm{p}<0.001)$ as compared to control $(90.1 \pm 9.4 \mathrm{~min}) .6$ Sensory block duration was highly significant in a group $(\mathrm{p}<0.001)$ while it was significant in group $C(p<0.05)$. The difference between to study group was also statistically significant $(p<0.001)$ in favor of dexmedetomidine. These findings are similar to Rani et al7 and Patil et al. ${ }^{[2]}$

In group, $\mathrm{D}$ mean time to regress the motor block to the modified Bromage 0 level was 244 minutes (Group D V/S Group NS; $<0.001$ ). In a group, $\mathrm{C}$ mean time to regress motor block to modified Bromage 0 level was 210 minutes (Group C V/S Group NS; $p=0.021$ ). In group NS mean time to regress motor block to modified Bromage 0 level is 192.67 minutes. Dexmedetomidine prolongs motor blockade significantly higher than Clonidine $(\mathrm{p}<0.001)$. The mechanism by which $1 \alpha 2$ adrenoceptor agonists prolong the motor-sensory block of local anesthetics is not well understood. It may be an additive or synergistic effect secondary to a different mechanism of action of the local anesthetic. The prolongation of the motor block of spinal anesthetics may result from the binding of $\alpha 2$ adrenoceptor agonists to motor neurons in the dorsal horn in the spinal cord. $^{[8]}$

Effective pain management is the most tangible judgment of anesthesiologist's capability. A spinal block is as good as gold to achieve anesthesia in lower limb surgeries. Drugs like dexmedetomidine and Clonidine, supported by the abovementioned data and similar studies, further add feathers in the crown.

Table 1: Parameters.

\begin{tabular}{|l|l|l|l|l|l|l|l|}
\hline \multirow{2}{*}{ Parameters } & Group D & Group C & Group NS & \multirow{2}{*}{ p-value } & $\begin{array}{l}\text { Group D } \\
\text { V/S } \\
\text { Group C }\end{array}$ & $\begin{array}{l}\text { Group D } \\
\text { V/S } \\
\text { Group NS }\end{array}$ & $\begin{array}{l}\text { Group C } \\
\text { V/S } \\
\text { Group NS }\end{array}$ \\
\cline { 2 - 6 } & Mean \pm SD & Mean \pm SD & Mean \pm SD & & & & \\
\hline Duration of postoperative analgesia & $275.33 \pm 29.33$ & $247.33 \pm 38.23$ & $219.33 \pm 16.60$ & $<0.001$ & 0.008 & $<0.001$ \\
\hline $\begin{array}{l}\text { Time of complete regression of } \\
\text { sensory block(S2 dermatome) }\end{array}$ & $336.67 \pm 29.40$ & $299.33 \pm 41.68$ & $274.67 \pm 19.07$ & $<0.001$ & 0.010 & $<0.001$ \\
\hline $\begin{array}{l}\text { Time of regression of motor } \\
\text { block(Bromage score zero) }\end{array}$ & $244.00 \pm 29.43$ & $210.00 \pm 28.04$ & $192.67 \pm 18.74$ & $<0.001$ & $<0.001$ & $<0.001$ \\
\hline
\end{tabular}




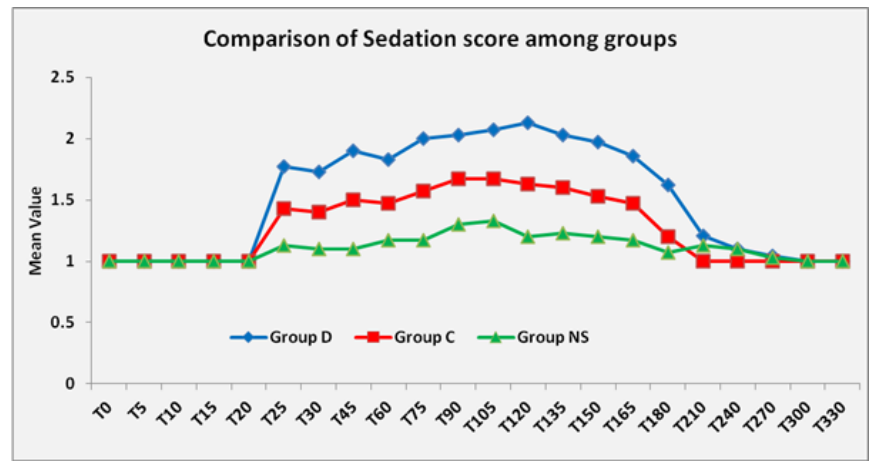

Figure 1: Comparison of modified Wilson sedation score among groups.

\section{Conclusion}

Dexmedetomidine $(1 \mu \mathrm{g} \mathrm{kg}-1)$ in comparison to clonidine $(2$ $\mu \mathrm{g} \mathrm{kg}-1)$ and placebo is far more effective in motor blockade, sensory blockade and duration of postoperative analgesia.

\section{References}

Copyright: $\odot$ the author(s), 2020. It is an open-access article distributed under the terms of the Creative Commons Attribution License (CC BY 4.0), which permits authors to retain ownership of the copyright for their content, and allow anyone to download, reuse, reprint, modify, distribute and/or copy the content as long as the original authors and source are cited.

How to cite this article: Bamel S, Kad N, Vinit, Popli S, Chahal DA. A Comparative Study of Intravenous Clonidine and Dexmedetomidine on Characteristics of Bupivacaine Spinal Anesthesia. Acad. Anesthesiol. Int. 2020;5(1):165-167.

DOI: dx.doi.org/10.21276/aan.2020.5.1.34

Source of Support: Nil, Conflict of Interest: None declared.
1. Chiari A, Eisenach JC. Spinal anaesthesia: Mechanisms, agents, methods, and safety. Regional Anesthesia and Pain Medicine.1998;23:357-362.

2. Patil KN, Adate KU, Saredesai SP. Evaluation and comparison of intravenous Clonidine and intravenous dexmedetomidine on duration of bupivacaine spinal anesthesia. Indian Journal of Clinical Anaesthesia. 2017;4(1): 64-68.

3. Breen TW, Shapiro T, Glass B, Foster-Payne D, Oriol NE. Epidural anesthesia for labor in an ambulatory patient.AnesthAnalg. 1993; 77(5):919-24. Sedation with Regional Anesthesia: Inter-Rater Agreement on a Modified Wilson Sedation Scale. Anesthesia Analg. 2002; 94:723-728.

5. Kumar KS, Kumar CA, K Murthy SG. A comparative prospective, randomized, double-blind study of the effect of iv dexmedetomidine on the subarachnoid block versus $0.9 \%$ normal saline as control. Sch. J. App. Med. Sci. 2014; 2(5A):1517-1523.

6. Jetley P, Khandelwal M, Bafna U, Sharma G, Jain S, Dutta D. Low-dose intravenous alpha-2 agonists as adjuvants to spinal levobupivacaine: A randomized study. Indian J Pain. 2017;31: 35-40.

7. Rani HL, Upendranath I. Comparative study of intravenous dexmedetomidine plus intrathecal bupivacaine vs intrathecal bupivacaine alone for prolongation of spinal analgesia. Journal of Evolution of Medical and Dental Sciences Nov 2015; 4:15952-9.

8. Eisanach JC, De Kock M, Klimscha W. a2 adrenergic agonists for regional anesthesia. Anesthesiology. 1996; 85: 655-74.
4. Némethy M, Paroli L, Russo W, Pamela G, Blanck, T. Assessing 